\title{
INFLUÊNCIA DA TEMPERATURA E DO SUBSTRATO NA GERMINAÇÃO DE SEMENTES DE Cariniana estrellensis (Raddi) Kuntze ${ }^{1}$
}

\author{
ANA CAROLINE KOPPER ${ }^{2}$, MARLENE DE MATOS MALAVASI ${ }^{3}$, \\ UBIRAJARA CONTRO MALAVASI ${ }^{3}$
}

\begin{abstract}
RESUMO - Foi quantificado o efeito da temperatura e do substrato na germinação de sementes de Cariniana estrellensis (Raddi) Kuntze. O delineamento adotado foi o inteiramente casualizado em esquema fatorial $2 \times 2 \times 3$ composto por duas temperaturas $\left(25^{\circ} \mathrm{C}\right.$ e $30-20^{\circ} \mathrm{C}$ ambas com fotoperíodo de $8 / 16$ horas), dois substratos (sobre areia e sobre papel filtro), e três lotes, utilizando-se quatro repetições de 25 sementes para cada combinação dos tratamentos. Os parâmetros analisados foram porcentagens de germinação (de plântulas normais, de plântulas anormais), velocidade média e tempo médio de germinação. Enquanto a temperatura não interferiu na porcentagem de germinação (sementes que emitiram radícula), maior porcentagem de plântulas normais $(65,8 \%)$ e menor porcentagem de plântulas anormais $(16,5 \%)$ foram anotadas com a utilização de temperatura constante de 25 ${ }^{\circ} \mathrm{C}$ e o substrato sobre papel filtro. Sementes de lote com maior teor inicial de água $(10,3 \%)$ e massa de mil sementes $(8,91 \mathrm{~g})$ resultaram em menor velocidade média e maior tempo médio de germinação. A procedência das sementes de diferentes matrizes interferiu nos resultados indicando a necessária de novos estudos quanto à origem destas diferenças germinativas.
\end{abstract}

Termos para indexação: sementes florestais nativas, qualidade fisiológica, jequitibá-branco, Lecythidaceae.

\section{INFLUENCE OF TEMPERATURE AND SUBSTRATE ON Cariniana estrellensis (Raddi) Kuntze SEED GERMINATION}

\begin{abstract}
It was quantified the influence of temperature and substrate on the germination of Cariniana estrellensis (Raddi) Kuntze seeds. The experiments used a completely randomized factorial experimental design involving a constant $25^{\circ} \mathrm{C}$ thermoperiod or alternating $30^{\circ} \mathrm{C} / 20$ ${ }^{\circ} \mathrm{C}$ thermoperiod (both with a $8 \mathrm{~h}$ light: $16 \mathrm{~h}$ dark photoperiod), sand or filter paper substrates, and seeds from three mature trees. All experiments used four replicates of 25 seeds each. Evaluations included percentage germination (radicle $\geq 2 \mathrm{~mm}$ ), percentages of normal and abnormal seedlings, mean germination, speed and mean germination time. While temperature did not alter the percentage germination a constant temperature of $25{ }^{\circ} \mathrm{C}$ on filter paper resulted in a higher percentage germination of normal seedlings with radical protrusion $(65.8 \%)$ and a smaller percentage of abnormal seedlings $(16.5 \%)$. Moreover, seeds with the highest water content $(10.3 \%)$ and mass of a thousand seeds $(8.91 \mathrm{~g})$ resulted in the lowest germination speed
\end{abstract}

${ }^{1}$ Submetido em 17/09/2009. Aceito para publicação em 15/05/2009.

${ }^{2}$ Bióloga, Mestre em Agronomia.
${ }^{3}$ Professor Unioeste - CCA, Marechal Cândido Rondon, PR, 85960-000,umala@unioeste; malavasi@unioeste.br. 
and the highest mean germination time. We concluded that the seed lot characteristics interfered with the results, indicating the need for further investigation into germinative differences from different provenances of the same tree species.

Index terms: jequitibá-branco, Lecythidaceae, native forest seeds, physiological quality.

\section{INTRODUÇÃO}

Cariniana estrellensis (Raddi) Kuntze, também conhecida como jequitibá-branco, bingueiro, cachimbeiro ou estopeira pertencente à família Lecythidaceae ocorrendo do sul da Bahia até o Rio Grande do Sul, no Acre e no Brasil Central, além do Peru, Bolívia e Paraguai. A espécie apresenta atributos madeireiros, apícolas, medicinais, e ecológicos sendo indicada em reflorestamentos para recuperação ambiental (Lorenzi, 1992; Carvalho, 1994). De acordo com os autores retro citados, a germinação das sementes de Cariniana estrellensis é epígea e abundante nas primeiras semanas da colheita (95\%), iniciando entre 6 e 70 dias após a semeadura, enquanto a emergência das plântulas ocorre entre 12 e 25 dias.

A germinação pode ser entendida como fenômeno biológico de retomada do crescimento do eixo embrionário que, nas sementes ortodoxas fora interrompido por ocasião da maturidade fisiológica resultando no rompimento do tegumento pela radícula (Carvalho e Nakagawa, 2000; Labouriau, 1983). Os tecnólogos de sementes, entretanto, reconhecem a semente como germinada apenas após ter formado plântula com tamanho suficiente para que se possa avaliar a normalidade de suas partes e a sua possibilidade de sobrevivência sob condições favoráveis de campo (Brasil, 1992).

Diversos fatores internos e externos à semente podem interferir na germinação (Malavasi, 1988; Marcos Filho, 2005). A temperatura interfere diretamente no processo tanto no que se refere à germinação total como à velocidade $\mathrm{e}$ uniformidade de germinação, devido à atuação na velocidade de absorção de água e também nas reações bioquímicas que determinam todo o processo de germinação (Carvalho e Nakagawa, 2000; Castro et al., 2004). De acordo com Bewley e Black (1994), a germinação das sementes de cada espécie ocorre sob uma determinada amplitude de temperatura, existindo uma temperatura ótima, na qual o processo se realiza mais rápido e eficientemente. Para germinação da maioria das sementes de espécies cultivadas, a temperatura ótima localiza-se na faixa de 20 a $30^{\circ} \mathrm{C}$ (Marcos Filho, 2005). A resposta germinativa pode ser ainda mais favorável, para determinadas espécies, dependente da condição de exposição à temperatura testada, se constante ou alternada (Carvalho e
Nakagawa, 2000).

Com relação ao substrato, Popinigis (1977) afirmou que pode haver variação de alguns fatores, tais como aeração, estrutura, capacidade de retenção de água e grau de infestação de patógenos. O substrato pode, assim, interferir na germinação por fornecer água e oxigênio, além de suporte físico para o desenvolvimento das plântulas.

As regras para análise de sementes recomendam o uso de papel, pano, areia ou solo como substrato para a germinação das sementes; a escolha deve considerar o tamanho da semente, sua exigência de água, sua sensibilidade à luz e a facilidade à contagem e avaliação das plântulas (Brasil, 1992).

Considerando-se a importância da temperatura e do substrato para a germinação, objetivou-se com este trabalho avaliar o efeito destes fatores na germinação de sementes de Cariniana estrellensis (Raddi) Kuntze coletadas de diferentes árvores matrizes.

\section{MATERIAL E MÉTODOS}

Sementes de jequitibá-branco foram obtidas de frutos de três matrizes localizadas nos municípios de Marechal Cândido Rondon (401 m, 24³2’42”S, 05402’35”W), Mercedes (375 m de altitude, latitude $24^{\circ} 26^{\prime} 38,2^{\prime \prime} \mathrm{S}$ e longitude $054^{\circ} 11^{\prime} 27,3^{\prime \prime} \mathrm{W}$ ) e de Quatro Pontes (448 m, $24^{\circ} 35^{\prime} 35^{\prime}$ 'S e $054^{\circ} 57^{\prime} 00^{\prime} \mathrm{W}$ ), região oeste do estado do Paraná denominados de lote 1 , lote 2 e lote 3 .

Para a caracterização dos lotes, determinou-se o teor inicial de água das sementes pelo método de estufa a $105{ }^{\circ} \mathrm{C} \pm 3{ }^{\circ} \mathrm{C}$ por 24 horas (Brasil, 1992) em quatro repetições de $2 \mathrm{~g}$ de sementes inteiras com base na massa de matéria úmida, e a massa de mil sementes em quatro repetições de 100 sementes em face da quantidade de sementes disponível.

Após a coleta, os frutos permaneceram em ambiente coberto e ventilado até completa deiscência das sementes as quais foram beneficiadas com retirada manual das alas. Os tratamentos foram mantidos em BOD nas condições de temperatura $20-30{ }^{\circ} \mathrm{C}$ alternadas ou $25{ }^{\circ} \mathrm{C}$ constante e fotoperíodo de $8 \mathrm{~h}$ luz e $16 \mathrm{~h}$ escuro, sendo realizadas avaliações diárias até o $47^{\circ}$ dia após semeadura quando 
cessou qualquer germinação.

$\mathrm{O}$ ensaio foi conduzido em delineamento inteiramente casualizado utilizaram-se quatro repetições de 25 sementes por combinação dos tratamentos que passaram por procedimento fitossanitário (solução de hipoclorito de sódio a $10 \%$ por 10 minutos, seguido de lavagem com água destilada).

Os substratos foram esterilizados em autoclave por 30 minutos a $120^{\circ} \mathrm{C}$. A quantidade de areia utilizada foi de $4 \mathrm{Kg}$ por bandeja, sendo a mesma embebida com $800 \mathrm{~mL}$ de água destilada enquanto as duas folhas de papel filtro foram embebidas com 2,5 vezes o seu peso, em caixas plásticas tipo "gerbox". A posterior adição diária de água foi executada à medida do necessário para conservação da umidade.

As avaliações constaram da emissão da radícula ( $\geq 2 \mathrm{~mm}$ ), formação de plântulas normais (com todas as estruturas essenciais) e anormais. Com base nos dados finais de cada parâmetro obtidos até o $47^{\circ}$ dia após a semeadura foram calculadas, respectivamente, a porcentagem de germinação, e as porcentagens de plântulas normais e anormais. Computouse ainda a velocidade média (VM) e o tempo médio (TM) de germinação de acordo com Labouriau (1983).

Os dados percentuais foram transformados em arcoseno raiz quadrada de $\mathrm{x} / 100$ e submetidos à análise de variância utilizando o programa SANEST (Zonta e Machado, 1984). As médias foram comparadas pelo teste de Tukey a $5 \%$ de confiabilidade.

\section{RESULTADOS E DISCUSSÃO}

Houve diferença significativa entre os lotes tanto no teor de água quanto na massa de mil sementes (Tabela 1). Essas diferenças podem resultar de fatores de crescimento assim como das características genéticas das sementes (Malavasi, 1988).

TABELA 1. Teor de água inicial e massa de mil sementes em lotes de sementes de jequitibá-branco.

\begin{tabular}{lccc}
\hline & $\begin{array}{c}\text { Matriz Mal.Cândido } \\
\text { Rondon } \\
\text { (lote 1) }\end{array}$ & $\begin{array}{c}\text { Matriz } \\
\text { Mercedes } \\
\text { (lote 2) }\end{array}$ & $\begin{array}{c}\text { Matriz Quatro } \\
\text { Pontes } \\
\text { (lote 3) }\end{array}$ \\
\hline $\begin{array}{l}\text { Teor de água } \\
\text { inicial (\%) }\end{array}$ & $9,5 \mathrm{~B}$ & $10,3 \mathrm{~A}$ & $9,0 \mathrm{C}$ \\
\hline $\begin{array}{l}\text { Massa de mil } \\
\text { sementes (g) }\end{array}$ & $5,57 \mathrm{C}$ & $8,91 \mathrm{~A}$ & $7,83 \mathrm{~B}$ \\
\hline
\end{tabular}

$\overline{\text { Médias seguidas da mesma letra na linha não diferem entre si pelo teste de }}$ Tukey a $5 \%$ de probabilidade.
Para os parâmetros porcentagem de germinação $(\mathrm{G})$ de plântulas normais (PN) e de plântulas anormais (PAN) não houve influência das temperaturas, enquanto o tipo de substrato (S) e o lote (L) influenciaram não só os resultados de (G) de maneira isolada, como também os resultados de (PN) e (PAN) através da interação $(\mathrm{S}) \mathrm{x}(\mathrm{L})$.

A maior porcentagem de germinação $93,4 \%$ foi obtida para as sementes do lote 1 coletadas no município de Marechal Cândido Rondon, enquanto para as dos lotes 2 e 3 foram observados valores de $74,3 \%$ e $71,6 \%$, respectivamente. Quanto às diferenças encontradas na germinação de lotes de procedências distintas, elas podem ocorrer, conforme Wielewicki et al. (2006) devido: 1) a grande variabilidade genética que espécies silvestres em seu estado natural comportam e que resultam em ampla variedade de características morfofisiológicas que, por sua vez, são determinantes no comportamento ecológico dos indivíduos de mesma espécie; 2) distribuição em grande extensão geográfica, sujeitando essas espécies a variações edafoclimáticas em escalas espaciais e temporais; e, 3) manejo de coleta e pós-coleta capaz de influenciar diretamente na qualidade germinativa das sementes.

A germinação sobre papel $(82,7 \%)$ foi maior do que aquela sobre areia $(76,1 \%)$. Os resultados mais satisfatórios com o substrato sobre papel indicam que este proporcionou de alguma forma vantagens germinativas às sementes de Cariniana estrellensis (Raddi) Kuntze. Por tratar-se de um ambiente fechado (em caixas "gerbox"), a umidade do substrato sobre papel foi mais bem conservada e desta forma, houve disponibilidade constante de água para as sementes. No substrato sobre papel, respostas germinativas positivas também foram encontradas para Mimosa caesalpiniaefolia Benth. (Novembre et al., 2007).

O desdobramento da interação entre os efeitos do lote e do substrato revelou que a germinação sobre papel resultou em maior número de plântulas normais e menor número de plântulas anormais comparada ao substrato sobre areia (Tabela 2). O efeito do substrato sobre areia foi o de amplificar diferenças na porcentagem de plântulas anormais originadas de sementes coletadas de matriz localizada no município de Quatro Pontes (lote 3). As diferenças no teor inicial de água e massa de mil sementes nos lotes de três procedências de sementes de jequitibá-branco influenciaram nas porcentagens de plântulas normais e anormais indicando a necessidade de considerar aquele fator ao aferir a qualidade de sementes de Cariniana estrellensis.

A análise de variância dos parâmetros velocidade média (VM) e tempo médio (TM) de germinação resultou em efeitos estatisticamente significativos isolados das três fontes de variação. 
TABELA 2. Porcentagens de plântulas normais (PN) e anormais (PAN) de jequitibá branco em função do lote e do substrato.

\begin{tabular}{lllllll}
\hline & \multicolumn{3}{c}{ PN(\%) } & \multicolumn{3}{c}{ PAN (\%) } \\
\hline & Lote 1 & Lote 2 & Lote 3 & Lote 1 & Lote 2 & Lote 3 \\
\hline Sobre papel & $60,1 \mathrm{Ba}$ & $62,4 \mathrm{ABa}$ & $75,1 \mathrm{Aa}$ & $14,0 \mathrm{Ab}$ & $14,2 \mathrm{Ab}$ & $21,3 \mathrm{Ab}$ \\
Sobre areia & $42,3 \mathrm{Ab}$ & $40,2 \mathrm{Ab}$ & $32,1 \mathrm{Ab}$ & $26,0 \mathrm{Ba}$ & $32,3 \mathrm{Ba}$ & $57,4 \mathrm{Aa}$ \\
\hline
\end{tabular}

Médias seguidas da mesma letra minúscula nas colunas e maiúsculas nas linhas não diferem pelo teste de Tukey a $5 \%$.

A velocidade média de germinação (VM) de sementes de jequitibá-branco foi maior com o uso da temperatura constante de $25^{\circ} \mathrm{C}$ e substrato sobre papel, e significativamente mais lenta com sementes do lote 2 do que com as dos outros lotes (Figura 1). As sementes do lote 2 originadas de matriz localizada em Mercedes possuíam maior tamanho médio e, portanto, a relação entre superfície e o volume da semente diminui, resultando no fato de que estas podem ser incapazes de obter água suficiente para iniciar o processo de germinação.

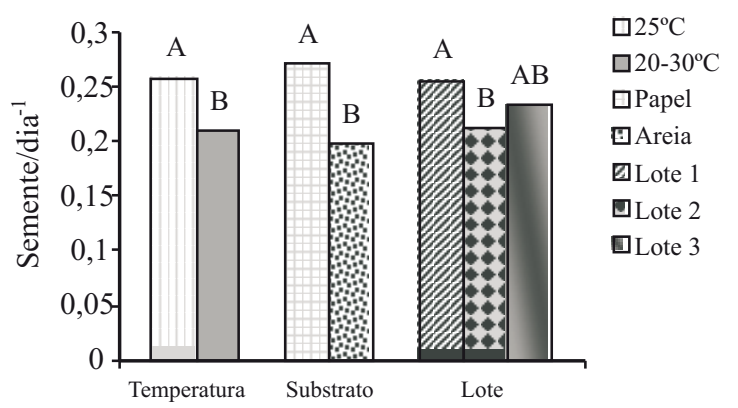

FIGURA 1. Velocidade média (semente/dia ${ }^{-1}$ ) de germinação de sementes de jequitibábranco em função da temperatura, do substrato e do lote.

O tempo médio (TM) de germinação mostrou ser estatisticamente menor com temperatura constante de $25^{\circ} \mathrm{C}$, e substrato sobre papel, assim como maior com sementes dos lotes 2 e 3 (Figura 2).

Os resultados com a utilização do substrato sobre papel indicam vantagens na germinação das sementes de Cariniana estrellensis (Raddi) Kuntze em um ambiente fechado (caixas tipo "gerbox") possivelmente resultante da maior disponiblidade de umidade do que no substrato sobre areia. Argumentação similar foi explicitada por Andrade et al. (2006) e Varela et al. (2005) que obtiveram melhores respostas germinativas com sementes de Dalbergia nigra (Vell.) Fr.
All. e Acosmium nitens (Vog.) Yakovlev, respectivamente, semeadas sobre vermiculita. No substrato sobre papel, maior porcentagem de germinação foi também encontrada para Mimosa caesalpiniaefolia Benth (Novembre et al., 2007).

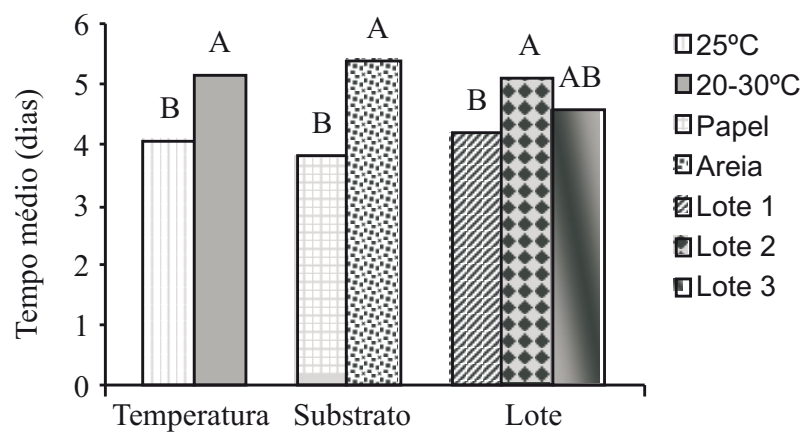

FIGURA 2. Tempo médio de germinação (dias) de sementes de jequitibá-branco em função da temperatura, substrato e lote.

Segundo Marcos Filho (2005), se após o inicio da absorção de água pela semente ocorrer indisponibilidade hídrica para continuidade do metabolismo a germinação é paralisada. O re-estabelecimento do suprimento de água deve ser o mais rápido possível, pois do contrário ocorre liberação de exsudados que estimula o desenvolvimento de fungos prejudicando a germinação.

As diferenças encontradas na germinação de lotes de procedências distintas da mesma espécie podem ocorrer, conforme Wielewicki et al. (2006), devido à variabilidade genética das espécies florestais silvestres, ou ainda devido a fatores correlacionados à coleta e ao beneficiamento de sementes.

A maior germinação obtida com sementes de jequitibá branco à temperatura constante de $25{ }^{\circ} \mathrm{C}$ não corrobora a afirmação de que a germinação de sementes florestais sob temperaturas alternadas que simulam as flutuações térmicas 
do solo florestal são melhores (Oliveira et al.,1996). Para Bilia et al. (1995) a maior velocidade de germinação de sementes de Cariniana estrellenses (Raddi.) Kuntze foi encontrada sob a temperatura constante de $30{ }^{\circ} \mathrm{C}$. Em Cariniana legalis (Martius) Kuntze, dentre as temperaturas testadas de 20, 25, $30,20-30$ e $35^{\circ} \mathrm{C}$, Rêgo e Possamai (2004) verificaram maior velocidade e porcentagem de germinação sob $30^{\circ} \mathrm{C}$ e $20-30$ ${ }^{\circ} \mathrm{C}$.

Neste trabalho, os resultados demonstraram que as sementes de Cariniana estrellensis (Raddi) Kuntze não necessitam de alternância de temperatura para iniciar, mas podem acelerar o processo germinativo. A alternância de temperatura também não favoreceu a germinação de sementes de Cedrela odorata L.(Andrade e Pereira, 1994) e de Acacia polyphylla DC (Araújo Neto et al., 2003), sendo que da mesma forma que em Cariniana estrellensis (Raddi) Kuntze houve apenas diferença significativa entre $25{ }^{\circ} \mathrm{C}$ constante e $30-20{ }^{\circ} \mathrm{C}$ alternada para tempo médio e velocidade média de germinação. Para Myracrodruon urundeuva Fr. All. (Pacheco et al., 2006) também foram encontrados resultados favoráveis à germinação sob temperatura constante nos quesitos porcentagem de germinação e primeira contagem.

\section{CONCLUSÕES}

A germinação de sementes de jequitiba branco não é influenciada pelo uso de temperatura constante $\left(25^{\circ} \mathrm{C}\right)$ ou alternada $\left(30-20{ }^{\circ} \mathrm{C}\right)$ com fotoperíodo de $8 / 16$ horas. No entanto, a temperatura constante de $25^{\circ} \mathrm{C}$ e o substrato "sobre papel" resulta em maior velocidade média e menor tempo médio de germinação de sementes de Cariniana estrellensis (Raddi) Kuntze. A utilização do substrato "sobre papel" possibilita a porcentagem máxima de plântulas normais.

\section{AGRADECIMENTOS}

À Fundação Araucária e a Capes pela concessão de bolsa para a primeira autora. Ao Núcleo de Estações Experimentais da UNIOESTE pela coleta das sementes.

\section{REFERÊNCIAS}

ANDRADE, A.C.S.; PEREIRA, T.S. Efeito do substrato e da temperatura na germinação e no vigor de sementes de cedro - Cedrela odorata L. (Meliaceae). Revista Brasileira de Sementes, v.16, p.34-40, 1994.

ANDRADE, A.C.S.; PEREIRA, T.S.; FERNANDES, M.J.; CRUZ, A.P.M.; CARVALHO, A.S.R. Substrato, temperatura de germinação e desenvolvimento pós-seminal de sementes de Dalbergia nigra. Pesquisa Agropecuária Brasileira, v.41, n.3, p.517-523, 2006.

ARAÚJO NETO, J.C.; AGUIAR, I.B.; FERREIRA, VILMA, M. Efeito da temperatura e da luz na germinação de sementes de Acacia polyphylla DC. Revista Brasileira de Botânica, v.26, n.2, p.249-256, 2003.

BEWLEY, J.D.; BLACK, M. Seeds: physiology of development and germination. New York: Plenum Press, 1994. 445p.

BILIA,D.A.C.;BARBEDO,C.J.;COICEV,L.;GUIMARÃES, F.L.C.; MALUF, A.M. Germinação de sementes de Cedrela fissilis Vell. e Cariniana estrellensis (Raddi) Kuntze - Efeito da Luz e temperatura. In: CONGRESSO NACIONAL DE BOTÂNICA, 46, Ribeirão Preto, 22/27 ja. 1995. Resumos. Ribeirão Preto, 1995. p.225.

BRASIL. Ministério da Agricultura e Reforma Agrária. Secretaria Nacional de Defesa Agropecuária. Departamento Nacional de Produção Vegetal. Coordenação de Laboratório Vegetal. Regras para Análise de Sementes. Brasília, DF, 1992. 365p.

CARVALHO, N.M.; NAKAGAWA, J. Sementes: ciência, tecnologia e produção. 4.ed. Jaboticabal: Funep, 2000. 588p.

CARVALHO, P.E.R. Espécies florestais brasileiras: recomendações silviculturais, potencialidades e uso da madeira. Colombo: Embrapa-CNPF; Brasília, DF: EmbrapaSPI, 1994. 638p.

CASTRO, R.D.; BRADFORD, K.J.; HILHORST, H.W.M. Embebição e reativação do metabolismo. In: FERREIRA, A. G.; BORGHETTI, F. (Org.) Germinação: do básico ao aplicado. Porto Alegre: Artmed, 2004. p.149-162.

LABOURIAU, L.G. A germinação de sementes. Washington: OEA, 1983. 174p.

LORENZI, H. Árvores brasileiras: manual de identificação e cultivo de plantas arbóreas nativas do Brasil. v.1. Nova Odessa: Plantarum, 1992. 352p.

MALAVASI, M.M. Germinação de sementes. In: PIÑARODRIGUES, F.C.M. (Coord.) Manual de análise de sementes florestais. Campinas: Fundação Cargill, 1988. p. $25-40$.

MARCOS FILHO, J. Fisiologia de sementes de plantas cultivadas. Piracicaba: FEALQ, 2005. 495p.

NOVEMBRE, A.D.L.C.; FARIA, T.C.; PINTO, D.H.V.; CHAMMA, H.M.C.P. Teste de germinação de sementes de sansão-do-campo (Mimosa caesalpiniaefolia Benth. Fabaceae-Mimosoideae). Revista Brasileira de Sementes, v.29, n.3, p.47-51, 2007. 
OLIVEIRA, E. de C.; PIÑA-RODRIGUES, F.C.M.; FIGLIOLIA, M.B. Propostas para a padronização de metodologias em análise de sementes florestais. Revista Brasileira de Sementes, v.11, n.1/2/3, p.1- 42, 1996.

PACHECO, M.V.; MATOS, V.P.; FERREIRA, R.L.C.; FELICIANO, A.L.P.; PINTO, K.M.S. Efeito de temperaturas e substratos na germinação de sementes de Myracrodruon urundeuva Fr. All. (Anacardiaceae). Revista Árvore, v.30, n.3, p.359-367, 2006.

POPINIGIS, F. Fisiologia da semente. Brasília, DF: AGIPLAN, 1977, 289p.

RÊGO, G.M.; POSSAMAI, E. Efeito do substrato e da temperatura sobre a germinação e vigor de sementes do jequitibá-rosa (Cariniana legalis). Colombo: Embrapa
Florestas, 2004. 2p. (Embrapa Florestas. (Comunicado técnico, 127).

VARELA,V.P.; COSTA, S.S.; RAMOS, M.B.P. Influência da temperatura e do substrato na germinação de sementes de itaubarana (Acosmium nitens (Vog.) Yakovlev) Leguminosae, Caesalpinoideae. Acta Amazônica, v.35, n.1, p.35-39, 2005.

WIELEWICKI, A.P.; LEONHARDT, C.; SCHLINDWEIN, G.; MEDEIROS, A.C.S. Proposta de padrões de germinação e teor de água para sementes de algumas espécies florestais presentes na região sul do Brasil. Revista Brasileira de Sementes, v.28, n.3, p.191-197, 2006.

ZONTA, P.; MACHADO,A.A. Sistema de análise estatística para microcomputadores - Sanest, Pelotas: UFPel, 1984. $94 \mathrm{p}$. 